\title{
TRIBOLOGY IN THE CORE OF A SODIUM-COOLED FAST BREEDER REACTOR*
}

E. WILD and K. J. MACK

Institut für Reaktorbauelemente, Gesellschaft für Kernforschung, Karlsruhe (Germany)

(Received May 9, 1975)

\section{Summary}

The construction of safe and reliable Liquid Metal Cooled Fast Breeder Reactor plants involves knowledge of the friction and wear behavior of different materials in contact with or sliding against each other. Friction and wear problems have been investigated as part of a still continuing program to provide guidelines for reactor designers.

Following initial experiments to select materials resistant to sodium corrosion and wear, wear rate as a function of the geometrical probe arrangements has been studied.

The frictional characteristics of different probe arrangements at various sodium temperature under different movements with varied dwell times were investigated. The materials tested included Stellite 6, Hastelloy C, Inconel 718, Nimonic 90 and 10 CrMoNiNb 910.

\section{Introduction}

Results of conventional wear tests cannot be applied to the detailed design requirements of the core and components of a Liquid Metal Cooled Fast Breeder Reactor (LMFBR). These reactors require mechanisms operating in various sodium liquid and sodium vapor environments for extended periods of time up to temperatures of $600{ }^{\circ} \mathrm{C}$ under different chemical properties of the fluid. The operational feasibility of many design features and mechanisms depends upon the trouble free sliding behavior of contacting metallic surfaces. The motion originates from operating necessities, from different thermal expansion and mechanically or flow induced vibrations. The problems include the pins in the fuel element bundles and the tubes of heat exchangers or steam generators supported by different types of spacers. Relative motions can take place between the pins or tubes and the spacers at high frequencies and with different amplitudes due to thermal expansions. Control rods as well as fuel element handling machines must

*Paper presented at the 3rd International Tribology Conference, "Tribology for the Eighties", Paisley, 22 - 25 September, 1975. 

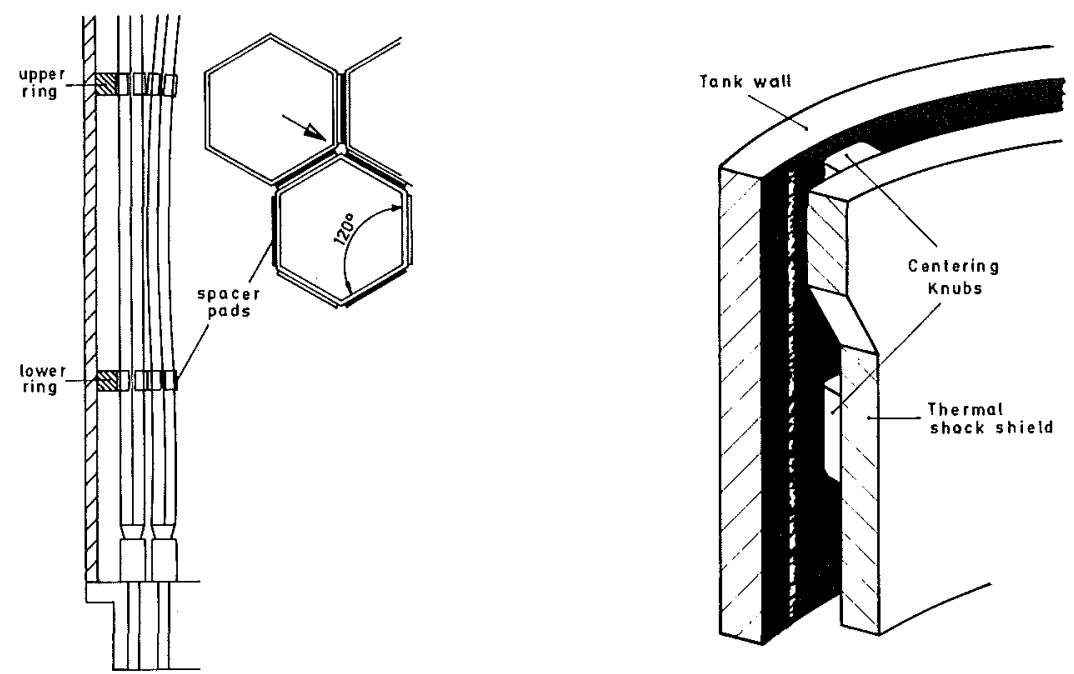

Fig. 1. Arrangement of fuel element duct pads (SNR 300).

Fig. 2. Thermal shock shield (KNK2).

work under all possible conditions with varying times of intermediate dwell.

At present the dominant problems are in the core restraint system. The insertion or extraction of one or several fuel elements causes an elastic process of adaptability over a part of the core cross-sectional area. Scram or different burnup may cause additive relative motions among the duct pads which separate the fuel element boxes in the core. The assemblies must move freely in all directions for reactor safety. Therefore it is necessary to understand friction and wear aspects of possible movements shown in detail in Fig. 1.

With axial displacement (arrow) each single element, because of its hexagonal primary form, acts as a wedge with an angle of $120^{\circ}$, corresponding to a friction angle of $30^{\circ}$. The friction coefficient of $\mu=\tan 30^{\circ}=$ 0.577 means self-locking of the respective system. Therefore it must be kept $\leqslant 0.5$. In LMFBR, high thermal conductivity could lead to thermal shocks on vessel walls and thermal shields are mounted, centered against the tank wall by knubs as shown in Fig. 2. Over a long period of operation no relative motion appears between the knubs and the tank wall and selfwelding may be expected. Following a sudden temperature transient the junction will be torn apart resulting in surface deterioration caused by an adhesive wear process [1]. With the expected total number of scrams local wear scars may seriously reduce the tank wall thickness.

In all cases similar dominant problems lead to the following demands:

(a) corrosion resistant materials with low wear rates which are dimensionally stable to prevent coolant channel blockages,

(b) materials with low activatable components to prevent contamination of coolant circuits,

(c) low friction materials to guarantee free relative motion between 
sliding components. Selfwelding under static contact must be avoided. In this respect characteristic phenomena have different effects, for example low oxygen content of the liquid metal is necessary to avoid corrosion but low oxygen content promotes selfwelding and impairs the friction behavior of materials.

To study the problems and to provide design data, friction and wear experiments have been carried out in Europe, U.S.A. and Japan. A number of screening tests have been carried out $[2,3]$. Also, the behavior of especially low friction materials was studied under a wider scope of parameters. With respect to the control rod guides the characteristic of motion and the specimen geometry were investigated; the sliding distance was of special interest.

To examine tank wall surface deterioration by the centering knubs of the thermal shock shield, experiments were carried out with different dwell times. The friction problems between fuel element duct pads were examined by studying the friction coefficient as a function of varying sodium temperature and different dwell times under standard conditions (surface pressure $\approx 1 \mathrm{kp} / \mathrm{mm}^{2}$, sliding distance $\approx 100 \mathrm{~m}$; duration of test $\approx 120 \mathrm{~h}$ ).

The importance of oxygen content of the sodium, sodium temperature and surface chemistry to the wear and friction behavior of surfaces made it necessary to run tests exceeding the duration of standard experiments.

\section{Equipment}

The problems outlined were studied in sodium loop systems with different probe arrangements, especially designed for the problems under investigation [4].

Figure 3 shows the equipment to carry out friction experiments simulating sodium conditions anticipated in the core of a Fast Breeder Reactor. The loop consists of a sodium supply and purification circuit and the different components. There are four parallel test circuits with one test section each. The flat linear induction pump maintains a sodium flow of up to $1 \mathrm{~kg} / \mathrm{s}$. Due to surface corrosion problems, during the entire test program the oxygen content of the sodium was maintained at approx. 3 - 5 p.p.m. It was continuously measured by a Liquid Metal Oxygen Meter and intermittently by plugging meters. Sodium samples for analysis were taken and compared with the monitor readings $[5,6]$.

\section{Test section (plane contact geometry)}

For "pin on plate" testing the device shown in Fig. 4(a) was constructed. To realize continuously rotating or oscillating motion a force is applied on the upper part of a vertical shaft driving the specimen holder $\mathrm{S}$ at the lower part, about $200 \mathrm{~mm}$ below the sodium level. The lower specimen holder $\mathrm{K}$ moves on an axial ball bearing against a bending lever, the deviation of which, as a function of the friction coefficient can be measured by a deviation amplifier. 


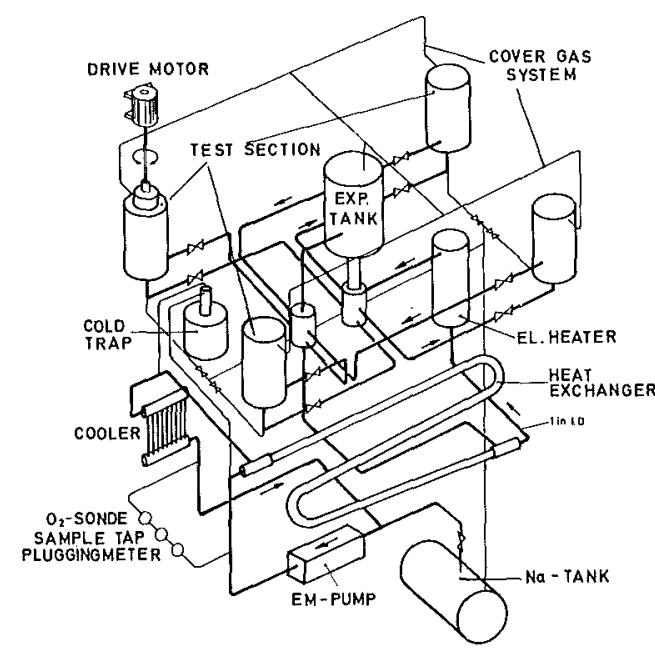

Fig. 3. Sodium wear test rig NVPII.

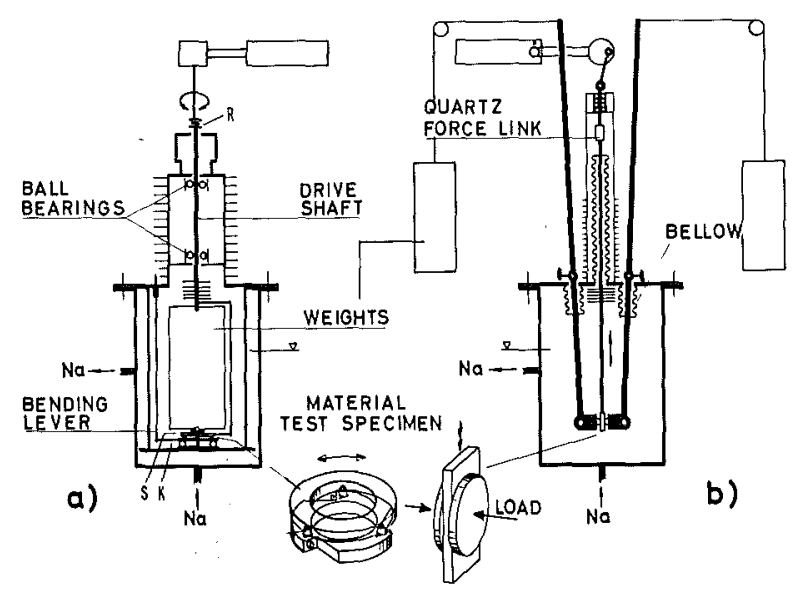

Fig. 4. Friction test sections.

A torque indicator $\mathrm{R}$ is mounted in the vertical drive shaft.

With this installation it is possible to measure friction force in two lines simultaneously. Errors caused by malfunction of any test section component or by condensation of sodium vapor in the cover gas seal can be reliably detected. By a varying combination of the friction force detector cells three different stages of rigidity of the system can be maintained:

(1) active cell; bending lever with deviation amplifier,

(2) active cell; drive shaft with torque indicator,

(3) pos. 1 and 2 simultaneously.

This has been of special interest for experiments to analyse the stick-slip friction behavior of materials. 


\section{"Plate on plate" configuration}

This is realized in the test section shown in Fig. 4(b). In a bracket system two flat specimens are pressed against a central plate oscillating vertically. The reciprocating motion of the vertical shaft and attached specimen is generated by a drive system outside the test chamber. The forces required to drive the shaft up and down are continuously measured by a quartz crystal. The weight of the shaft is compensated by a defined covergas pressure inside the test vessel. Measuring pulses of both systems are transferred to the amplifiers then to the visicorder or to the compensation writer.

\section{Parameters of interest}

To investigate the effect of different frictional conditions on the wear rate and friction coefficient of materials a series of tests was performed in high purity sodium under oscillating relative motion. Based on the environmental and contact conditions expected in a fast breeder reactor core operating conditions are shown in Table 1.

TABLE 1

Operating conditions

\begin{tabular}{ll}
\hline Variable & Constant \\
\hline stroke length: $2 ; 5 ; 10 \mathrm{~mm}$ & surface pressure: $0.8 / 1.2 \mathrm{kp} / \mathrm{mm}^{2}$ \\
travel distance: $2-100 \mathrm{~m}$ & slid. velocity: $120 \mathrm{~mm} / \mathrm{min}$ \\
Na-temperature: $250^{\circ} / 400^{\circ} / 600^{\circ} \mathrm{C}$. & $O_{2}$-content in Na: $3-5 \mathrm{ppm}$ \\
spec. geometries: 3 pins, $3 \mathrm{~mm} \phi$ & Na-velocity: $0.5 \mathrm{~m} / \mathrm{s}$ \\
flat $/$ spherical & \\
plate on plate $12 \times 15 \mathrm{~mm}$ & \\
\hline
\end{tabular}

\section{Materials}

The influence of different parameters on friction behavior was investigated with cobalt and nickelbase alloys of acceptable low wear rates shown by previous screening test. These included Hastelloy C, Nimonic 90, Stellite $6 \mathrm{H}$, Inconel 718 and the ferritic material $10 \mathrm{CrMoNiNb} 910$. The nickel alloy wear specimens were fabricated from heat treated material. Samples of cast Stellite 6 on welded Stellite 6 were tested after comparison of hot hardness, structure and chemical analysis.

\section{Experimental results}

\subsection{Influence of stroke length}

Hastelloy $\mathrm{C}$ tests under oscillating relative motion with variable stroke length showed an increase in surface deterioration with decreasing amplitude. 


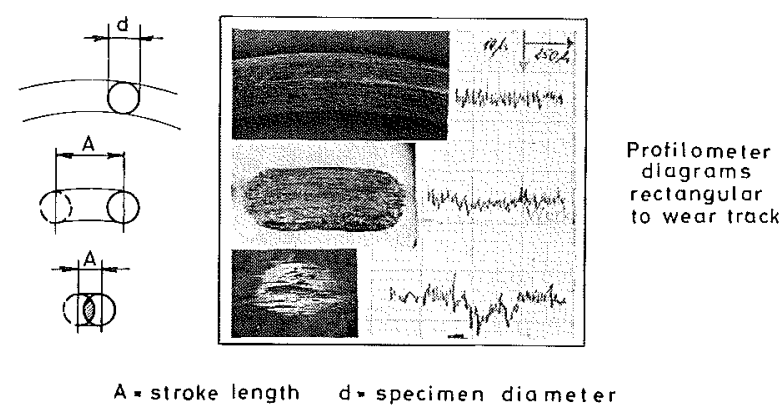

Fig. 5. Hastelloy C plate wear surface.

Figure 5 shows the three different wear scars, caused by a constant number of friction cycles. Of vital importance is not only the stroke length, but also the relation between stroke length $A$ and specimen diameter $d$ in the direction of movement. Wear particles not removed from the sliding interface are mainly responsible for the development of friction characteristics. This situation occurs if the ratio $A / d$ approximates to a value $<1$. The results are relevant to friction between fuel element duct pads.

\subsection{Influence of geometry}

With like materials, Inconel 718 and Hastelloy C respectively, experiments were carried out to investigate the influence of different specimen geometries. The wear rate of probes with flat and spherical ends, both sliding on a flat disk were compared. Table 2 shows the measured wear rates as a function of geometry. Much more material is removed by wear from the flat disks than from the pin specimens. Comparing flat and spherical pins a greater loss of material was indicated with the spherical probes; this phenomena seems to be due to a work hardening process.

TABLE 2

Wear rate as a function of geometry

\begin{tabular}{llrrl}
\hline & Pin spher. & 6.88 & 19.08 & \\
Hastelloy C & Plate & 12.20 & & Wear rate \\
& Pin flat & 1.30 & 15.70 & \\
& Plate & 14.40 & & \\
& Pin spher. & 5.46 & 19.46 & $\mathrm{~cm}^{3} / \mathrm{cm}-\mathrm{kp}$ \\
Inconel 718 & Plate & 14.00 & & $\times 10^{-10}$ \\
& Pin flat & 3.80 & 16.9 & \\
\hline
\end{tabular}

\subsection{Influence of travel distance}

The interpretation of friction and wear data becomes complicated, displacement is not constant during the wear in process. Figure 6 shows friction coefficients of materials in $400{ }^{\circ} \mathrm{C}$ sodium from the initiation of 


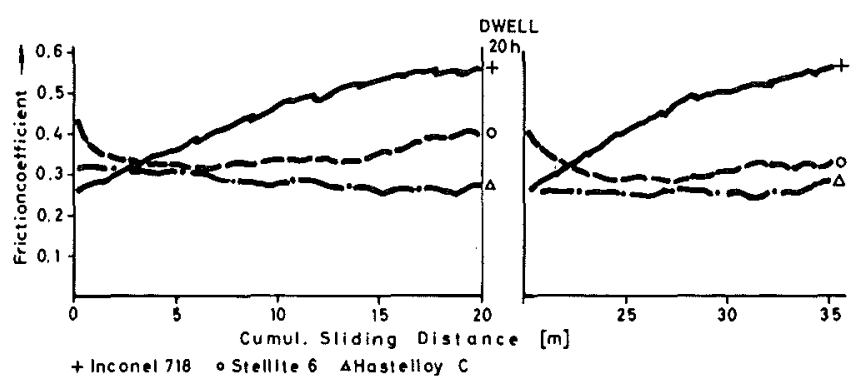

Fig. 6. Typical friction diagrams.

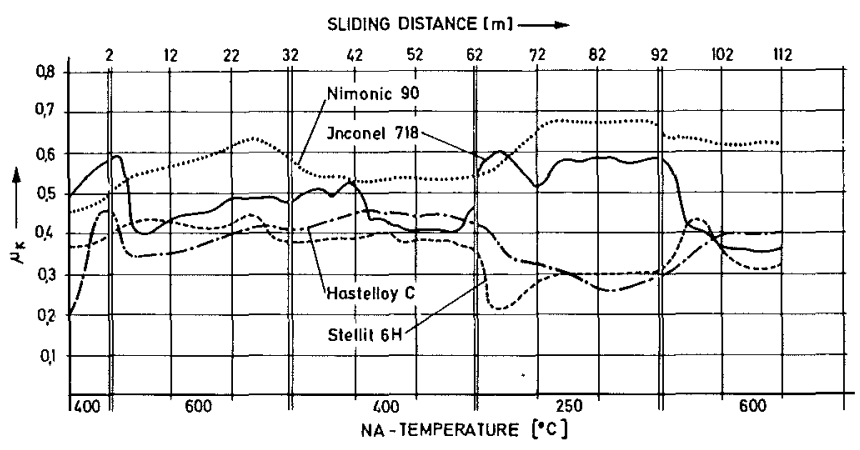

Fig. 7. Friction coefficients (av.).

relative motion to a cumulative rubbing distance of 20 and $35 \mathrm{~m}$ respectively with an intermediate dwell time. The diagram could give rather a qualitative impression of the distribution of friction in a specific way for each single material tested.

The friction coefficient of Stellite 6 shows a tendency to fail after overcoming a recognizable breakaway. The initial friction coefficient of Inconel 718 was relatively low $(0.2-0.25)$ but increased to values exceeding the limit 0.5 required by reactor designers. In subsequent tests running continuously to a sliding distance of $100 \mathrm{~m}$, after an initial period of low values the friction coefficient increased and remained constant at $0.55-0.6$.

\subsection{Influence of Na-temperature}

The average dynamic friction coefficients of materials measured in different test facilities at similar Na-temperatures followed no specific pattern (Fig. 7). For each material a significant influence of temperature is evident. Figure 8 for example shows the friction diagrams of Stellite 6 at $250^{\circ}, 400^{\circ}$ and $600{ }^{\circ} \mathrm{C}$. Whilst the average dynamic friction at $600{ }^{\circ} \mathrm{C}$ is similar to that at $400{ }^{\circ} \mathrm{C}$ the maximum friction coefficient significantly increased with increasing temperature. This is due to a time controlled stickslip type frictional behavior; the classical form of stick-slip arises whenever the static coefficient of friction is markedly greater than the kinetic coefficient $[7,8]$. Considering only a small part of the stick-slip diagram 


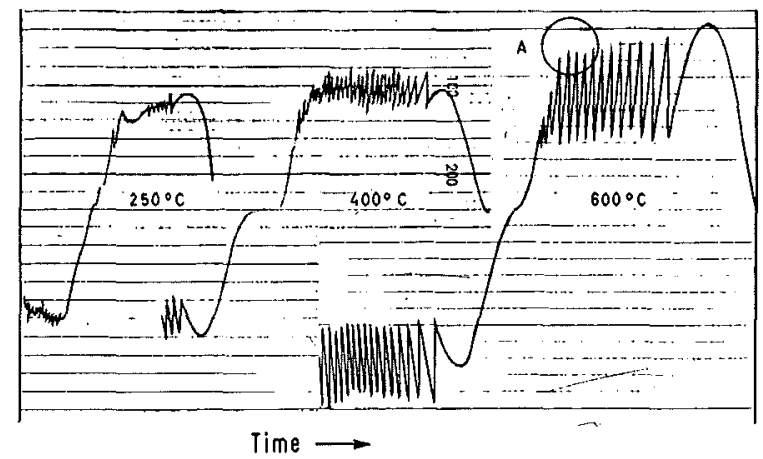

Fig. 8. Friction coefficient of Stellite 6 in liquid sodium at different temperatures (oscillating relative motion $\pm 5 \mathrm{~mm}$ ).

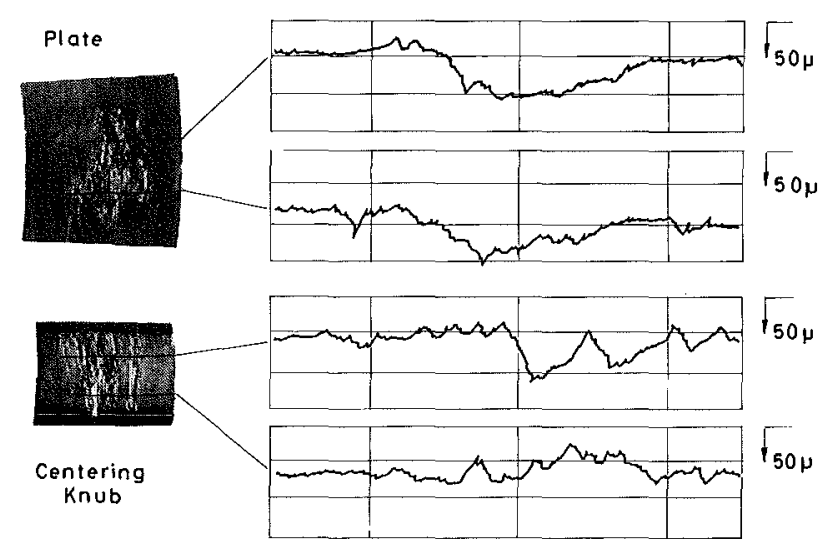

Fig. 9. Surface profiles of centering knub and tank wall simulating plate.

(Fig. 8A) each single peak represents a maximum static friction for a very short time interval. It is known that sliding velocity or the elasticity of the test section driving system can remarkably effect the stick-slip friction behavior of materials.

\subsection{Influence of combined effects}

The effect of static contact and oscillating relative motion alternating in a chronological order was studied. To shorten the program, two cycles were carried out at a time following a defined period of dwell. A significant difference was found in comparing the maximum (static) friction coefficient of the first and the second cycles respectively. Surface deterioration, Fig. 9, was measured by a profilometer. Wear scars not deeper than $75 \mu \mathrm{m}$ were found after 300 cycles, whilst in a parallel test a maximum surface roughness of $68 \mu \mathrm{m}$ after 10 cycles, and of $80 \mu \mathrm{m}$ after 30 cycles were measured.

\subsection{Influence of surface corrosion}

Using Stellite 6 the influence of surface corrosion on the friction 


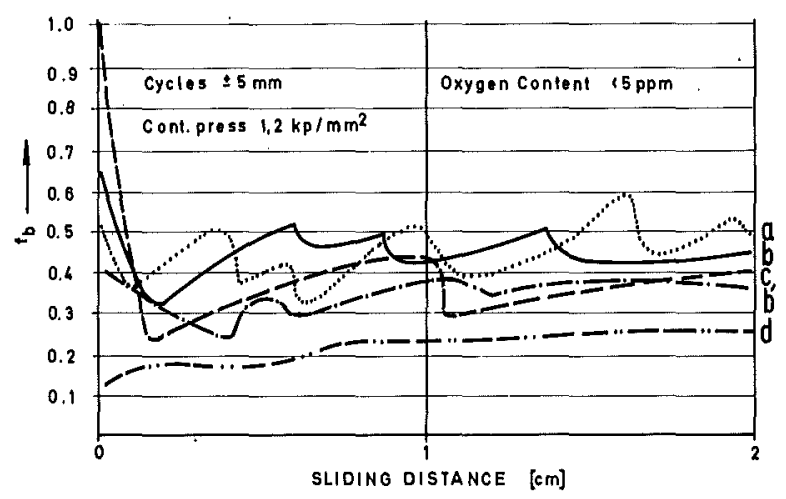

Fig. 10. Breakaway and subsequent sliding friction after dwell of $1800 \mathrm{~h}$ at $550{ }^{\circ} \mathrm{C}$.

coefficient was studied. The dominant parameter was the dwell time, varying from 150 to $1800 \mathrm{~h}$. During dwell the probes were in static contact under a load $\left(1.2 \mathrm{kp} / \mathrm{mm}^{2}\right)$ at $550{ }^{\circ} \mathrm{C}$.

Typical results obtained in four parallel tests are shown in Fig. 10.

Tests (a), (b) and (c) were started after $1800 \mathrm{~h}$ of dwell; scatter of the breakaway friction coefficient from 0.5 to 1.0 is apparent. Test (b) was continued for an additional $100 \mathrm{~h}$. The breakaway friction was 0.4 . One of the test specimens (d) was taken out of the test vessel, cleaned and reassembled after the $1800 \mathrm{~h}$ of dwell. The start up friction was 0.13 , increasing slowly due to the subsequent sliding process.

\section{Conclusion}

From the results, the wear rate and friction coefficient measured for a definite type of motion cannot automatically be transferred to friction processes under a different type of motion. This means that the friction or wear coefficient of material combinations can be indicated as a general value only for a definite frictional condition.

Experiments with motion amplitudes equal to or smaller than the diameter of the body in motion have shown that distinct cavities may be partly generated by the retention of the abraded particles resulting in high friction and wear coefficients. This knowledge is of special significance to the pads between the fuel element boxes where particularly unfavorable frictional conditions prevail.

Two essential conclusions can be drawn from the results concerning the design of guide or centering elements. (1) Using friction couples of ductile materials (like on like) material abrasion is not implicitly proportional to the friction path or sliding distance. A permanent mutual transfer of material between the contacting surfaces occurs without an appreciable loss of weight of the respective parts. This process depends on the type of relative movement and in the capability of the flow medium to remove the abrasion products from the friction zone. (2) With harder materials a greater 
effect of wear will be observed on the component having the longer slip line which is only partly covered by the mating material.

The friction coefficient of the nickel and cobalt base materials considered varied at varying temperatures; no regular pattern could be detected. However; a feature common to all materials is a tendency towards stick-slip at high temperatures dependent on various factors. Reduction in sliding speed caused an increase in the stick-slip amplitudes (mass acceleration, times of stationary contact).

Increased rigidity of the moving and measuring systems yielded an appreciable reduction in stick-slip.

When the contact pressure only was varied, the relationship was maintained between the average friction coefficient and the width of the stick-slip curve band (between $\mu_{\max }$ and $\mu_{\min }$ ). Typical stick-slip confirmed almost clean metallic rubbing interfaces. with no influence of $\mathrm{Na}$-adsorption being recognized. From the experiments executed to investigate the influence of surface corrosion it was found that breakaway friction coefficients are not proportional to the dwell time. Values of $\mu \approx 1.0$ were indicated after $200 \mathrm{~h}$ as well as after $1800 \mathrm{~h}$, unfortunately with a broad band of scatter. But for this type of selfwelding, generated during the time of static contact, a complicated combination of different parameters is evident, mainly creep of material and diffusion effected by temperature and time [9].

To solve the problems still outstanding in this field extensive experiments are being carried out at the Gesellschaft für Kernforschung including the mechanical and chemical stability of precorroded surfaces, the regeneration capability of such layers and the metallurgical means to influence corrosion of the sliding surfaces.

\section{References}

1 W. J. Freede, L. Newcomb and R. S. Kennedy, Static and sliding contact behavior of materials in sodium environments at elevated temperatures, NAA-SR-12446 (1967).

2 E. Wild, K. J. Mack and H. Hoffmann, Experimentelle Untersuchungen des Verschleissverhaltens von Stählen und Legierungen in Na, KFK-1252 (1970).

3 W. Dietz, H. Weber and E. Wild, Friction behavior of Inconel 718 and Stellite 6 as fuel assembly duct pad materials, IAEA/SM-173/VII-1973.

4 E. Wild, K. J. Mack and G. Drechsler, Das Verschleissverhalten von Werkstoffen in flüssigem Natrium. Versuchseinrichtungen und experimentelle Ergebnisse, KFK-1659 (1972).

5 H. U. Borgstedt, G. Drechsler, G. Frees and G. Wittig, Erfahrungen mit elektrochemischen Sauerstoffsonden in Natrium-kreissläufen, ATW, July (1974).

6 H. U. Borgstedt, Z. Perić and G. Wittig, Anlage zur Natriumdestillation für analytische Zwecke "NADESTAN 4", KFK-1941, Feb. (1974).

7 E. Rabinowicz, Friction and Wear of Materials, John Wiley, New York, 1966.

8 F. P. Bowden and D. Tabor, Reibung und Schmierung fester Körper, Springer Verlag Göttingen, 1959.

9 F. Huber, K. Mattes and H. Weinhold, Selbstversehweissen von Strukturwerkstoffen in flüssigem Natrium, KFK-1903, Feb. (1974). 